\title{
Offshore telemedicine emergency service: a 1-year experience
}

\author{
Giulio Mastella ${ }^{1} \cdot$ Lars Darstein $^{2} \cdot$ Carsten Raufhake $^{3} \cdot$ Vera Schneider $^{1} \cdot$ Anna Corletto $^{1} \cdot$ Alessandra Buiatti $^{1}$. \\ Alexander Müller ${ }^{1} \cdot$ Franziska Schuessler-Hahn $^{4} \cdot$ Markus Gondert $^{5} \cdot$ Heiko Gerdes $^{2} \cdot$ Eimo Martens $^{1}$
}

Received: 30 September 2020 / Accepted: 4 March 2021 / Published online: 23 March 2021

(C) The Author(s) 2021

\begin{abstract}
Aim Offshore wind energy is a fast growing market. Accordingly, a correspondingly large number of employees are working at the wind farms. Owing to the harsh operating conditions, accidents and medical emergencies occur there. The care of these patients poses special challenges. The aim of the investigation was to determine whether telemedical emergency care is technically possible on the North Sea, far away from any medical care.

Subject and methods We were able to establish a raw data supported telemedical integration with a rescue service monitor for transmission of ECG, blood pressure, saturation and other vital parameters to a telemedicine centre. As a first step, a satellite connection was set up on a supply ship for the transmission, which was then made available for data transfer via WLAN.

Results In this project, we were able to show in tests as well as in actual patient care that telemedical support of rescue service personnel on site using raw data transmission is also possible offshore on a supply ship. In this project, defined areas with WLAN coverage were necessary in which the transmission worked in $100 \%$ of cases.

Conclusion The care of emergencies in the area of offshore wind farms is an increasing problem, which can be sensibly treated with telemedical support. Technical possibilities can also be created on site in the North Sea. The further expansion of a communication network, for example, with LTE or 5G, is necessary to enable telemedical care independent of supply ships.
\end{abstract}

Keywords Remote-monitoring $\cdot$ Offshore $\cdot$ Telemedicine $\cdot$ Emergency medical service $\cdot$ Defibrillator $\cdot$ Digital health $\cdot$ Wind farm

\section{Introduction}

In Germany, the Paris Agreement on $\mathrm{CO}_{2}$ reduction has led to the commissioning and construction of wind turbines in the North and Baltic Sea. Such wind turbines are grouped in windmill platforms in German waters, mainly outside the 12 nautical mile zone in the exclusive economic zone (EEZ) (United Nations. Office of the Special Representative of the Secretary-General for the Law of the Sea 1986). This

Eimo Martens

Eimo.martens@mri.tum.de

1 Clinic for Cardiology, Klinikum rechts der Isar, Technical University Munich, Ismaninger Str. 22, 81675 Munich, Germany

2 Offshore \& Medical Service GmbH, Norden, Germany

3 Department of Anesthaesiology, HELIOS clinic Cuxhaven, Cuxhaven, Germany

4 Medical Department, Cardiology, Charite, Berlin, Germany

5 Emergency Department, Berufsgenossenschaftliches Krankenhaus, Berlin, Germany economical sector has been massively expanding in the past few years, such that since 2004 more than 30 wind farms (Table 1) have been established up to 200 miles off the German coast and more are in planning. The turbines installed to date supply a total of more than $7000 \mathrm{MW}$ of electrical energy annually (deCastro et al. 2019; Pichitkul et al. 2019).

In the past few years, up to 7600 employees from different branches have been working daily on the platforms (Marlene et al. 2018) and the number is expected to increase to over 10,000 employees in the course of next year. This number corresponds to the populations of an average small town with its own emergency service. Many of the employees live on base platforms in the wind farms and change their shift every $2-4$ weeks. Other employees are brought to the area of operation daily with special supply ships or helicopters. This special workplace situation alone results in particular illnesses and stressful situations for employees (Mette et al. 2018). No studies have been published to date about the exact number of accidents or emergencies on offshore wind farms. Nevertheless, Piotrowski et al. (Piotrowski et al. 2016) described that the main sources of health risks on offshore stations are temperature, electromagnetic field, 
Table 1 Offshore windfarms in the North Sea until 2020

\begin{tabular}{|c|c|}
\hline Year built & Offshore windpark \\
\hline 2019 & $\begin{array}{l}\text { Deutsche Bucht (under construction) } \\
\text { Borkum II (under construction) } \\
\text { Hohe See (under construction) } \\
\text { Albatros } \\
\text { Merkur Offshore (under construction) }\end{array}$ \\
\hline 2018 & $\begin{array}{l}\text { Borkum Riffgrund } 2 \\
\text { Arkona }\end{array}$ \\
\hline 2017 & $\begin{array}{l}\text { Wikinger } \\
\text { Nordsee One } \\
\text { Nordergründe } \\
\text { Veja Mate } \\
\text { Sandbank }\end{array}$ \\
\hline 2016 & $\begin{array}{l}\text { Gode Wind } 2 \\
\text { Gode Wind } 1\end{array}$ \\
\hline 2015 & $\begin{array}{l}\text { Amrumbank West } \\
\text { Riffgrund } 1 \\
\text { Butendiek } \\
\text { Trianel Windpark Borkum } \\
\text { Nordsee Ost } \\
\text { Dan Tysk } \\
\text { Global Tech } 1 \\
\text { Baltic } 2\end{array}$ \\
\hline 2014 & $\begin{array}{l}\text { Meerwind Süd/Ost } \\
\text { Riffgat }\end{array}$ \\
\hline 2013 & Bard Offshore 1 \\
\hline 2011 & Baltic \\
\hline 2010 & Alpha ventus \\
\hline 2008 & Hooksiel (Pilot, dismanteled in 2016) \\
\hline 2006 & Breitling (Pilot) \\
\hline 2004 & Offshore Project Ems-Emden (Pilot) \\
\hline
\end{tabular}

noise from operating wind turbines, direct and alternating current, and chemicals.

It is of crucial importance to guarantee these workers occupational safety in critical working conditions, including ensuring a proper and structured first aid system. As part of the further expansion of personnel in recent years, a rescue service with specialised emergency paramedics has been established on almost all platforms.

A similar approach has been developed in the past few years for the personnel working on oil platforms (Mair et al. 2008). At the beginning of the telemedical era, medical consulting to these stations was granted via radio or phone links (Ponsonby et al. 2009). Precedent studies (Webster et al. 2008) have shown how a successively developed transmission of vital parameters could improve the decision-making path in relation to medical emergencies.
The First Aid department of the German Statutory accident insurance ("Deutsche Gesetzliche Unfallversicherung" DGUV) has established the project group 'Rescue and First Aid - offshore'. The aim of this project is to create uniform offshore standards regarding the qualification of first responders and medical personnel as well as first aid equipment (Stuhr et al. 2014).

The first aid, rescue and treatment of injured or sick workers is mostly subcontracted to private companies, operating in the field of rescue services, specialised in offshore emergencies and telemedicine. These companies provide an operational rescue service for the wind farms in the North Sea, $24 \mathrm{~h}$ a day, 7 days a week, because they cannot always be reached by the institutional ground-based rescue service from land. Moreover, civil air rescue is not well suited here due to the special requirements needed and the long distance. The same goes for water rescue (DGZRS, Deutsche Gesellschaft zur Rettung Schiffbrüchiger). Air and water rescue could help in rare emergencies but cannot be continuously removed from their actual area of operation in the long term. Furthermore, the rescue service of the German Navy is not in charge here.

Owing to the great distance and the privately organised service, the technical equipment of the supply ships, helicopters and platforms has been improved over the years. In case of emergency, a team of paramedics is brought to the injured person by ship or helicopter and once there has to decide about the right rescue equipment, the immediate care on site and, if necessary, the right target hospital on dry land. In the case immediate care on site is needed, the team of paramedics must provide the patient with emergency medication or delicate medical procedures such as intubation or resuscitation on site on their own (Dethleff et al. 2016; Stuhr et al. 2016).

Work-related illnesses have been steadily increasing in the western world in recent years. Occupational safety plays an essential role in this area with high physical workload for accident prevention, this naturally includes extensive safety measures in the area of the daily work of the employees on the wind frames. In addition to these measures, an upto-date emergency care on site is an essential part of the occupational safety concepts of the different wind farms and has to be constantly adapted to the current technical possibilities in order to prevent deterioration of the health situation due to the lack of supplies. Considering the number of employees, this is a relevant problem (Sakowski and Marcinkiewicz 2019).

In view of the significant expansion of offshore wind power and the extreme circumstances, telemedical care options for this area of application are urgently needed. In May 2018, an experimental project began on a support vessel employing a new generation monitor, the Zoll Series X (ZOLL 2016), as a trial model to be subsequently exported to the whole offshore wind parks. 


\section{Barriers}

Barriers to implementing telemedical models - especially remote monitoring - can be categorised in technical barriers, barriers to end-user acceptance, economical barriers and organisational barriers, i.e. the evaluation and quality management (Harst et al. 2019; van Dyk 2014).

In the care of critically ill patients on the high seas, the technical barrier is in the foreground and can be summarised as follows: (i) geographical distance because the Windfarms are located up to 200 miles off the German coast; (ii) unpredictable meteorological conditions, which can make the site unreachable for several hours; (iii) absence of emergency medicine physicians on site; (iv) absence of mobile phone or other network connection for mobile use.

In addition to the technical barriers, end-user acceptance is a particularly important issue in emergency situations. Here, a reliable telemedical operation with easy handling must be guaranteed. Windfarm workers must be trained to deal with emergencies and to integrate their first-aid knowledge with the employment of a telemedical infrastructure, such as monitors, mobile phones or similar devices, and access to an easy-to-use network system, in order to immediately share the gathered data. The training measures must also focus on the acceptance of the technology as a real support system when it is established.

Economic barriers play a subordinate role in this area of application - unlike in other areas of medical care - because the investments and operating costs in wind farms are extremely high for the operators.

Organisational barriers arise in the area of telemedical centres. A telemedical approach is nowadays diffused in most big hospitals and refers mainly to the treatment of outpatient cases or monitoring of implantable devices, such as pacemakers and defibrillators. This type of patient management only requires a daytime employment of trained personnel, for telephone interviews or remote supervision of the devices. Emergencies are still referred to the nearest emergency department. Continuous offers, with $24 \mathrm{~h}$ a day on call personnel, are currently available, for example, far away from the place of deployment in Berlin (BG Emergency Hospital) and Munich (Kl. Rechts der Isar). Centres on the coast are now also being established as part of projects.

\section{Objective}

Based on the difficult working conditions at the offshore wind farms and the different barriers, the aim of this project was to provide telemedical support for the emergency paramedic at the wind farm. This proof-of-concept study aimed to collect the subjects' vital signs early, monitor them over time and provide them to a physician in a telemedical centre on dryland to obtain a clear and complete clinical picture of the specific case and thus enable early and appropriate decision making. The medical classification of the emergencies treated and the follow up of the patients were not part of the aims of this preliminary trial. The difference in terms of improvement of the medical work-up with or without the telemedical approach was not described because all enrolled subjects were treated employing the described telemedical approach.

The project focused on determining the technical feasibility and accuracy of recording and transmitting vital signs using a portable defibrillator with monitoring capability (ZOLL® Series X) on a supply ship.

The concept is then to be exported to other offshore wind farms.

\section{Implementation}

At the beginning of the project, the focus was on establishing a network connection. The test equipment used (ZOLL® Xseries) has an integrated WLAN and LAN/Ethernet connection; therefore, one of the two methods had to be used. Owing to the mobility, the focus was on the WLAN connection. Within the scope of this proof-of-concept study, a satellite connection (Ku-Band \& Ka-Band, upload 1Mbi/s, download $8 \mathrm{Mbi} / \mathrm{s}$, maritime Internet) was established on a supply ship. This connection was then made available via router using WLAN and Ethernet in defined areas of the supply ship. The audio contact to the emergency paramedic was established by means of satellite telephone.

Multiple parameters are recorded and measured by the portable defibrillator with monitoring function. The resting ECG can be recorded in 3, 5 or 12 leads and printed on $80 \mathrm{~mm}$ thermal paper at variable speed $(25$ or $50 \mathrm{~mm} / \mathrm{s})$ as required. Depending on the automatic ECG analysis, the device can be used as an automatic external defibrillator (AED) after a recording time of $30 \mathrm{~s}$ (including battery charging time). If required, the defibrillator can be used in manual mode and in this configuration can be synchronised with the R-waves of the ECG and used for cardioversion. A maximum of 40 shocks at $200 \mathrm{~J}$ is guaranteed in battery mode. With the defibrillator paddles, a current of up to $140 \mathrm{~mA}$ can also be delivered for external pacing.

The oxygen saturation is measured with a pulse oximeter, which measures not only the heart rate but also the saturation of carboxyhemoglobin and methemoglobin. The $\mathrm{CO}_{2}$ partial pressure can be measured up to $150 \mathrm{mmHg}$ with an accuracy of $2 \mathrm{mmHg}$ to $38 \mathrm{mmHg}$ and $5 \mathrm{mmHg}$ to the maximum.

The measurement of non-invasive blood pressure can be started manually or set at regular intervals ( $1 \mathrm{~min}$ to $1 \mathrm{~h}$ ). The range of measured values reaches $260 \mathrm{mmHg}$ with an accuracy of $3 \mathrm{mmHg}$. The invasive pressure may have up to three separate channels (arterial, venous and intracerebral pressure). 
The temperature can be measured up to $50{ }^{\circ} \mathrm{C}$ with an accuracy of $0.1^{\circ} \mathrm{C}$ (ZOLL 2016).

\section{Methods}

Within the scope of this study all collected data (standardised in every measurement: ECG, $\mathrm{SpO} 2$, saturation of carboxyhemoglobin and methemoglobin, $\mathrm{CO}_{2}$, non-invasive blood pressure and temperature) were transferred to a telemedicine centre on dryland (BG Clinic Berlin, Klinikum rechts der Isar Munich) for testing. Stability of the connection and delay of the transmission for the whole duration of the process were used as parameters in order to determine the success or failure of the simulation. Although we had focused on test participants (28), we also had actual patients (12) who experienced medical emergencies during their working time on the supply ship. The volunteers accepted to have their vital parameters monitored over a preset amount of time (30 min), during their working shift. Twelve workers experienced medical emergencies during their duty time. Because none of these 12 emergencies was planned or foreseen, no preliminary data about the previous medical conditions of the workers who were enrolled was gathered.

\section{Results}

Between 2018 and 2019, 40 cases simulations (28) and emergency cases (12) were performed on board of the support vessel, at different times of the day, on different areas of the ship, either with Ethernet (8) or Wireless (32) connection, in order to test the efficacy of the connection and transmission of the recorded data. Before starting the investigation, different areas on the vessel were predefined depending on the presence of WLAN or LAN (ship's hospital, bridge, hangar, office, cabin 5131 and control room) connection. These data were simultaneously transmitted to a medical centre on dryland and were analysed there by the appointed physician.

The data were gathered and transmitted from different parts of the ship. In $100 \%$ of the transmissions in the predefined areas (34/34), the simulations and emergency cases were successful managed with the telemedicine centre without any connection problems. Six simulations on the deck failed because of poor wireless connection. The main problem reported was an unstable connection trough the ship's wireless coverage outside the predefined areas. Time of the day during the recording of the data did not impact the efficacy of the transmission.

A total of 12 cases were emergency cases that could be treated without any problems by transferring the data to a telemedicine centre (BG Hospital Berlin). With an existing network connection, the transmission of the monitored patient data via the satellite connection proved to be possible for the examiner without any significant time delay. The number of parameters recorded was not relevant because all mobile sensors were connected in all simulations. Outside of the defined areas either no connection or only an unstable connection with terminations was possible.

\section{Discussion}

The telemedical care of patients on the North Sea is possible with the system we tested and showed that the one major barrier - technical feasibility - can be overcome. In terms of end-user acceptance, room for improvement remains, including enhancing the network connection on the ship. The only variable that affected the result was the use of a defined location with a stable internet connection.

Our data has led to the fact that the operators of offshore wind farms want to establish a mobile phone coverage of the wind farms based on telecommunication connections to the supply platforms established by submarine cables. Within the framework of a follow-up project, it is now to be investigated whether the transmission of data via the offshore mobile radio network created specifically for this purpose is possible from the entire wind farm independently of a supply vessel. This would then be a solution that could be transferred to all new wind farms.

Should this procedure become more widespread, the expansion of existing or the establishment of new telemedicine centres with financial support from the wind farm operators will be indispensable.

In addition to the technical feasibility of transferring data from an offshore site, which we have tested, it is of course necessary in parallel to integrate this data into a clinical information system and thus into an electronic patient record. This is an elementary part of our further projects, especially in the area of integration of mobile sensor technology or telemedical raw data. Syntactic and semantic interoperability plays an essential role here (Bender and Sartipi 2013; Henkel and Spinner 2020; Pfaff et al. 2019), as does the broad availability of the data for the various service providers in intersectoral exchange. In various regions of the world, such digital patient records have already shown advantages in telemedical care (Almond et al. 2017; 2018). In particular, the transregional possibility of telemedical care also requires the transregional availability of patient data in a patient file protected by data protection law.

An economic classification of our examination of technical feasibility cannot be compared with the classical economic factors in the health care system. Here, the extreme location of the workplaces and the high costs of the entire facilities must be explicitly put in relation to the health care of the workers on site. Various evaluation systems, for example, 
from the Health Innovation Hub Berlin (HIH) or the National Institute for Health and Care Excellence (NICE), providesometimes controversial - guidelines here for the economy or evidence of digital care systems (Forsyth et al. 2021; Nwe et al. 2020). This is an important pillar in the evaluation of commercial care systems. Even if in our case a concrete economic evaluation of the approach is missing, the costs for digital transmission, including the corresponding equipment are certainly lower than a 24/7 staffing of the supply platforms with a corresponding emergency physician. Our primary goal in all our telemedicine assessments is to scientifically evaluate raw data and systems. In this work, we were able to demonstrate the technical feasibility and thus prove that monitoring signals (ECG, $\mathrm{SpO} 2$, etc.) that have been validated many times can be transmitted and evaluated in a meaningful way even over long distances. However, randomised studies for critical evaluation of the benefit are still pending.

Transferring the NICE specifications from the English health system to our system, a 'tier 3b' system could be used here; however, only the platform functionality of the technical feasibility 'tier 1' was tested in the first step, here the specifications for the availability of the service, possibility of monitoring and possibility of communication could be shown. Further factors such as the possibility of diagnosis and help with treatment are possible, but not scientifically tested here, and part of further studies (NICE 2019).

\section{Summary}

Emergencies in offshore wind farms are a relevant problem. Within the scope of our proof-of-concept study, we have already been able to provide medical care for 12 real emergencies and thus anticipate treatment decisions on site.

In the past, the use of any technical aids as an interface between patient and doctor was often criticised. Our study takes place in an area where the physical presence of the attending physician is not only difficult but also potentially dangerous because transporting the physician to the site of the emergency would in any case lead to a critical delay of the clinical treatment. Our data show that a telemedical approach to offshore emergency medicine is already possible and that the positive outcome of the diagnostic process depends in a unique way on the stability of the technical support. It is therefore important to also provide economic support for the development and dissemination of telecommunications infrastructures.

However, randomised trials to critically evaluate the benefits are still pending, as is an economic evaluation.

Author Contributions All authors contributed to the study conception and design. Material preparation, data collection and analysis were performed by Giulio Mastella, Heiko Gerdes and Eimo Martens. The first draft of the manuscript was written by Giulio Mastella and Eimo Martens and all authors commented on previous versions of the manuscript. All authors read and approved the final manuscript.

Funding Open Access funding enabed and orgranized by Projekt DEAL.

Availability of data and material (data transparency) Raw data available upon request.

Code availability Not applicable.

\section{Declarations}

Conflict of interest The authors declare that they have no conflict of interest in relation to this work.

Role of funding source The work has so far not been financially supported by any institution or company. It is planned to submit applications for research support as the project progresses.

Ethical approval This thesis deals with the technical feasibility of integrating offshore sensors to manage emergencies in offshore windfarms. In principle, no patient inclusion in the study was planned, but within the framework of the emergency operations, these data were evaluated retrospectively and anonymously. There is no ethics vote for this technical work. This study involving human participants was in accordance with the ethical standards of the institutional and national research committee and with the 1964 Helsinki Declaration and its later amendments or comparable ethical standards.

Informed consent/consent for publication Not needed.

Open Access This article is licensed under a Creative Commons Attribution 4.0 International License, which permits use, sharing, adaptation, distribution and reproduction in any medium or format, as long as you give appropriate credit to the original author(s) and the source, provide a link to the Creative Commons licence, and indicate if changes were made. The images or other third party material in this article are included in the article's Creative Commons licence, unless indicated otherwise in a credit line to the material. If material is not included in the article's Creative Commons licence and your intended use is not permitted by statutory regulation or exceeds the permitted use, you will need to obtain permission directly from the copyright holder. To view a copy of this licence, visit http://creativecommons.org/licenses/by/4.0/.

\section{References}

Almond H, Cummings E, Turner P (2017) An approach for enhancing adoption. Use and utility of shared digital health records in rural Australian communities. Stud Health Technol Inform 235:378-382

Almond H, Cummings E, Turner P (2018) Recommendations for Enhancing the Implementation and Utility of Shared Digital Health Records in Rural Australian Communities Stud Health Technol Inform 252:15-20

Bender D, Sartipi K (2013) HL 7 FHIR: an agile and RESTful approach to healthcare information exchange. In: Proceedings of the 26th IEEE International Symposium on Computer-Based Medical Systems, 20-22 June 2013, pp 326-331. https://doi.org/10.1109/CBMS. 2013.6627810 
deCastro M, Costoya X, Salvador S, Carvalho D, Gómez-Gesteira M, Sanz-Larruga FJ, Gimeno L (2019) An overview of offshore wind energy resources in Europe under present and future climate. Ann N Y Acad Sci 1436:70-97. https://doi.org/10.1111/nyas.13924

Dethleff D et al (2016) Air medical evacuations from the German North Sea wind farm bard offshore 1: traumatic injuries, acute diseases, and rescue process times (2011-2013). Air Med J 35:216-226. https://doi.org/10.1016/j.amj.2016.02.002

Forsyth JR, Chase H, Roberts NW, Armitage LC, Farmer AJ (2021) Application of the National Institute for Health and Care Excellence evidence standards framework for digital health technologies in assessing mobile-delivered technologies for the selfmanagement of type 2 diabetes mellitus: scoping review. JMIR Diabetes 6:e23687. https://doi.org/10.2196/23687

Harst L, Lantzsch H, Scheibe M (2019) Theories predicting end-user acceptance of telemedicine use: systematic review. J Med Internet Res 21:e13117. https://doi.org/10.2196/13117

Henkel AG, Spinner C (2020) IT-STRATEGIE: Digitalumbau bei laufendem Betrieb kma - Klinik Management aktuell 25:51-54. https://doi.org/10.1055/s-0040-1709870

Mair F, Fraser S, Ferguson J, Webster K (2008) Telemedicine via satellite to support offshore oil platforms. J Telemed Telecare 14:129-131. https://doi.org/10.1258/jtt.2008.003008

Marlene OS, Dietmar E, Ulrike L (2018) Ökonomische Indikatoren des Energiesystems - Methode, Abgrenzung und Ergebnisse für den Zeitraum 2000-2016. GWS - Institute of Economic Structures Research. https://www.bmwi.de/Redaktion/DE/Publikationen/ S t u di en/o e k on omis che-indikatoren-undenergiewirtschaftlichegesamtrechnung.pdf?__blob= publicationFile\&v $=18$. Accessed 2020

Mette J, Velasco Garrido M, Harth V, Preisser AM, Mache S (2018) Healthy offshore workforce? A qualitative study on offshore wind employees' occupational strain, health, and coping BMC Public Health 18:172. https://doi.org/10.1186/s12889-018-5079-4

NICE (2019) Evidence Standards Framework for Digital Health Technologies. https://www.nice.org.uk/Media/Default/About/whatwe-do/our-programmes/evidence-standards-framework/digitalevidence-standards-framework.pdf

Nwe K, Larsen ME, Nelissen N, Wong DC-W (2020) Medical mobile app classification using the National Institute for Health and Care Excellence evidence standards framework for digital health technologies: interrater reliability. Study J Med Internet Res 22:e17457. https://doi.org/10.2196/17457

Pfaff ER et al (2019) Fast healthcare interoperability resources (FHIR) as a meta model to integrate common data models: development of a tool and quantitative validation study. JMIR Med Inform 7:e15199. https://doi.org/10.2196/15199
Pichitkul A, Sankar LN, Jagoda J (2019) Feasibility of an offshore wind farm in the North Sea region. Proceedings of the ASME 2019 Gas Turbine India Conference. Volume 2: Combustion, Fuels, and Emissions; Renewable Energy: Solar and Wind; Inlets and Exhausts; Emerging Technologies: Hybrid Electric Propulsion and Alternate Power Generation; GT Operation and Maintenance; Materials and Manufacturing (Including Coatings, Composites, CMCs, Additive Manufacturing); Analytics and Digital Solutions for Gas Turbines/Rotating Machinery. Chennai, Tamil Nadu, India. December 5-6, 2019. V002T06A019. https://doi.org/10. 1115/GTINDIA2019-2783.

Piotrowski PJ, Robak S, Polewaczyk MM, Raczkowski R (2016) Offshore substation workers' exposure to harmful factors - actions minimizing risk of hazards. Med Pr 67:51-72. https://doi.org/10. 13075/mp.5893.00320

Ponsonby W, Mika F, Irons G (2009) Offshore industry: medical emergency response in the offshore oil and gas industry Occup Med (Lond) 59:298-303. https://doi.org/10.1093/occmed/kqp075

Sakowski P, Marcinkiewicz A (2019) Health promotion and prevention in occupational health systems in Europe. Int J Occup Med Environ Health 32:353-361. https://doi.org/10.13075/ijomeh.1896.01384

Stuhr M, Kraus G, Weinrich N, Jürgens C, Sefrin P (2014) Erste Hilfe in Offshore-Windparks in deutschen Gewässern Der Notarzt 30:159 168. https://doi.org/10.1055/s-0034-1370238

Stuhr M et al (2016) Medical emergency preparedness in offshore wind farms: new challenges in the german north and Baltic seas. Anaesthesist 65:369-379. https://doi.org/10.1007/s00101-0160154-7

United Nations. Office of the Special Representative of the SecretaryGeneral for the Law of the Sea (1986) The law of the sea: national legislation on the exclusive economic zone, the economic zone and the exclusive fishery zone. United Nations, New York

van Dyk L (2014) A review of telehealth service implementation frameworks. Int J Environ Res Public Health 11:1279-1298. https://doi. org/10.3390/ijerph110201279

Webster K, Fraser S, Mair F, Ferguson J (2008) A low-cost decision support network for electrocardiograph transmission from oil rigs in the North Sea. J Telemed Telecare 14:162-164. https://doi.org/ $10.1258 /$ jtt.2008.003021

ZOLL (2016) ZOLL X-series. ZOLL medical Deutschland GmbH. https://www.zoll.com/-/media/uploadedfiles/public_site/products/ x_series/xseries_spec-20sheet_de-pdf. Accessed 01.09.2020 2020

Publisher's Note Springer Nature remains neutral with regard to jurisdictional claims in published maps and institutional affiliations. 